\title{
Severe Heart Failure and Outcomes in 121 Children With Dilated Cardiomyopathy: A Single-Center Retrospective Study from Southwest China
}

\section{Cheng Chen}

The First Affiliated Hospital of Guangxi Medical University

\section{Danyan Su}

The First Affiliated Hospital of Guangxi Medical University

Suyuan Qin

The First Affiliated Hospital of Guangxi Medical University

\section{Bingbing Ye}

The First Affiliated Hospital of Guangxi Medical University

\section{Yanyun Huang}

The First Affiliated Hospital of Guangxi Medical University

\section{Weiying Zhao}

The First Affiliated Hospital of Guangxi Medical University

\section{Yuqin Huang}

The First Affiliated Hospital of Guangxi Medical University

\section{Dongli Liu}

The First Affiliated Hospital of Guangxi Medical University

\section{Yusheng Pang ( $\triangle$ pangyush@163.com)}

The First Affiliated Hospital of Guangxi Medical University

\section{Research Article}

Keywords: Dilated cardiomyopathy, heart failure, children, management, prognosis

Posted Date: February 24th, 2022

DOI: https://doi.org/10.21203/rs.3.rs-1352003/v1

License: (c) (i) This work is licensed under a Creative Commons Attribution 4.0 International License. Read Full License 


\section{Abstract \\ Objective}

Heart failure is a common complication in children with dilated cardiomyopathy. The aim of this study was to determine whether severe heart failure at diagnosis was related to poor outcomes in children with dilated cardiomyopathy.

\section{Methods}

We analyzed medical data from 121 children with dilated cardiomyopathy in our hospital from 2003 to 2021. The children were grouped by the degree of heart failure. Cox regression analysis was performed to confirm whether severe heart failure was associated with poor outcomes.

\section{Results}

There were 121 patients with dilated cardiomyopathy in this research. The mean age of the 121 patients was $118.5 \pm 63.0$ months. Of these patients, 81 (67.8\%) were sorted into a severe heart failure group and 39 (32.2\%) were placed into a mild heart failure group. A comparison between the two groups showed that patients with severe heart failure were older and more likely to be male, have lower systolic blood pressure measurements, be admitted to the intensive care unit and be treated with $\beta$-blockers, loop diuretics, spironolactone and digoxin. In addition, they had larger systolic and diastolic left ventricular end-diastolic dimensional and lower left ventricular ejection fractional z-scores as well as being more prone to aortic and tricuspid regurgitations ( $P<0.05$ in all cases). After adjusting for age, sex, heart rate, left ventricular ejection fraction z-scores and drug, severe heart failure was found to be independently associated with an increased risk of death (hazard ratio $[\mathrm{HR}] 2.27 ; \mathrm{P}<0.005$ ).

\section{Conclusions}

Severe heart failure at diagnosis was related to a greater risk of death in children with dilated cardiomyopathy. Further prospective studies are warranted to evaluate the efficacy between the treatment undertaken for heart failure and outcomes in children with dilated cardiomyopathy.

\section{Introduction}

Dilated cardiomyopathy (DCM) is a progressive and serious disorder of the heart muscle which is characterized by the dilation of the left ventricle accompanied by a reduction of systolic function[1]. DCM is diagnosed in 0.57 cases per 100000 children /year in the United States and has a $20 \%$ mortality rate at 1 year and a $56 \%$ mortality rate at 4 years $[2,3]$. Although the prognosis of children with DCM have 
increased in the past 20 years[4], the management of patients with this condition needed to be more targeted and precise in order to raise long-term prognosis.

Heart failure (HF) is a severe complication of DCM and a major cause of heart transplantation or sudden death in children with DCM $[2,5]$. Improvement of HF can reverse cardiac histologic remodeling and increase the prognosis of DCM[6,7]. With the release of the European Society of Cardiology and American College of Cardiology Guidelines for HF in 2021, the management of HF has become more standardized and effective[8,9]. Therefore, we performed a novel analysis comparing children with severe HF who were classified as ROSS/NYHA class III or class IV to those with mild HF who were classified as ROSS/NYHA class I or class II. We hypothesized that severe HF is related to poor prognosis in children with DCM.

\section{Methods}

\section{Study Subjects}

Children aged $\leq 18$ years with a diagnosis of DCM admitted to the First Affiliated Hospital of Guangxi Medical University between March 2003 and September 2021 were enrolled into the study. The exclusion criteria included $\otimes$ congenital heart disease, arrhythmia cardiomyopathy, ischemic heart disease, cardiac valve disease and hypertensive heart disease; $\square$ DCM with known etiology, such as drug-induced cardiomyopathy and inherited metabolic cardiomyopathy such as primary carnitine deficiency.

\section{Definitions}

Diagnosis of DCM was indicated by a left ventricular end-diastolic dimension (LVEDD) of more than two standard deviations (SDs) above normal for the individual's body surface area (or $z$-score for age $>2$ ) and a left ventricular ejection fraction (LVEF) or left ventricular fractional shortening (LVFS) of lower than 2 standard deviations for healthy children of the same age (or $z$-score for age $<2$ ). Severe HF was defined as an improved ROSS scoring criteria ( $\geq 7$ score)[10] or NYHA class III/IV and mild HF was defined as an improved ROSS scoring criteria ( $\$ 7$ score) or NYHA class I/II.

\section{Study Methods}

General data involved age, race, sex and body mass index (BMI), HF at diagnosis, duration of symptoms, duration of stay in hospital, multiple hospitalizations ( $\geq 2$ visits), admission to the intensive care unit, family history of DCM, heart rate at diagnosis, systolic and diastolic blood pressure measurements at diagnosis, echocardiographic measurements z-scores, medications, follow-up periods and outcomes. The patients were classified into either a severe and or a mild HF group based on the severity of HF. The primary adverse event was death.

\section{Statistical Analysis}

Data analyses were performed employing SPSS software (version 24.0 for Windows, SPSS, Inc., Chicago, Illinois). Data are presented either as means or percentages. Continuous variates were compared using 
Student's $t$ test (for normally distributed data) or Wilcoxon rank sum test (for non-normally distributed data), and categorical variates were compared with chi-square tests. Kaplan-Meier plots were established, and log-rank statistics were employed to evaluate survival differences at specific time points of 12, 24 and 60 months after enrollment as well as overall survival. Cox regression was performed to confirm the factors independently related to worse outcomes to reduce selection bias among children involved in the study. Hazard ratios (HR) and 95\% confidence intervals $(95 \% \mathrm{Cl})$ were used to present the data. $\mathrm{P}<0.05$ was identified statistically significant.

\section{Results}

\section{Clinical Characteristics}

There were 121 DCM patients in this cohort. The mean age of the 121 patients was $118.5 \pm 63.0$ months. Of these, 81 (67.8\%) patients were grouped as severe HF and 39 (32.2\%) were placed in a mild HF group. Table 1 presents the demographic information, clinical indicators, echocardiographic characteristics, medications used at the time of cardiomyopathy diagnosis, time period of follow-up and the outcomes of patients who were classified as severe HF compared with those who were classified as mild HF. There were no significant differences between the groups when compared by race, duration of symptoms, duration in the first hospitalization, multiplicity of hospitalizations, family history of DCM, BMI, heart rate and systolic blood pressure. Nevertheless, patients with severe HF were older, more likely to be male, have lower systolic pressure, be admitted to the intensive care unit and be treated with $\beta$-blockers, loop diuretics, spironolactone and digoxin. Patient with severe HF were more likely to have lower LVEF zscores, larger systolic and diastolic LV dimensional z-scores, and more likely to suffer from aortic and tricuspid regurgitations. 
Table 1

Demographics, clinical indicators, echocardiographic measurement, drug use, time of follow-up and Outcomes of the patients in this study.

\begin{tabular}{|c|c|c|c|c|}
\hline Parameter & $\begin{array}{l}\text { Overall }(n= \\
121)\end{array}$ & $\begin{array}{l}\text { Severe HF ( } \mathrm{n} \\
=82)\end{array}$ & $\begin{array}{l}\text { Mild HF }(n= \\
39)\end{array}$ & $p$ \\
\hline Age, $($ mean $\pm S D), m$ & $118.5 \pm 63.0$ & $129.5 \pm 64.5$ & $95.4 \pm 53.5$ & 0.005 \\
\hline Male, n (\%) & $69(57.0 \%)$ & $52(63.4 \%)$ & $17(43.5 \%)$ & 0.04 \\
\hline Race, n (\%) & & & & 0.865 \\
\hline Han & $58(47.9 \%)$ & $38(46.3 \%)$ & $20(51.3 \%)$ & \\
\hline Zhuang & $57(47.1 \%)$ & $40(48.8 \%)$ & $17(43.6 \%)$ & \\
\hline Others & $6(5.0 \%)$ & $4(4.9 \%)$ & $2(5.1 \%)$ & \\
\hline Duration of symptoms, (mean \pm SD), m & $4.0 \pm 9.6$ & $3.9 \pm 8.9$ & $4.2 \pm 11.1$ & 0.899 \\
\hline $\begin{array}{l}\text { Duration in first hospitalization, (mean } \pm \\
\text { SD), d }\end{array}$ & $11.8 \pm 10.4$ & $12.5 \pm 11.3$ & $10.5 \pm 8.0$ & 0.342 \\
\hline Multiple hospitalizations, n (\%) & $51(42.1 \%)$ & $39(47.6 \%)$ & $12(30.8 \%)$ & 0.08 \\
\hline Admission to intensive care unit, $\mathrm{n}(\%)$ & $53(43.8 \%)$ & $45(54.8 \%)$ & $8(20.5 \%)$ & $\dot{0.001}$ \\
\hline $\begin{array}{l}\text { Family history of dilated cardiomyopathy, } \\
n(\%)\end{array}$ & $10(8.3 \%)$ & $8(9.7 \%)$ & $2(5.1 \%)$ & 0.388 \\
\hline Body mass index, (mean \pm SD) & $16.3 \pm 3.3$ & $16.7 \pm 3.5$ & $15.6 \pm 2.6$ & 0.089 \\
\hline Heart rate at admission, (mean \pm SD) & $113.4 \pm 21.9$ & $114.2 \pm 20.8$ & $111.7 \pm 24.3$ & 0.574 \\
\hline $\begin{array}{l}\text { systolic blood pressure at admission, } \\
\text { (mean } \pm \text { SD) }\end{array}$ & $99.3 \pm 14.4$ & $97.2 \pm 14.4$ & $104.1 \pm 13.4$ & 0.017 \\
\hline $\begin{array}{l}\text { diastolic blood pressure at admission, } \\
\text { (mean } \pm \text { SD) }\end{array}$ & $64.8 \pm 11.5$ & $64.2 \pm 11.5$ & $66.1 \pm 11.6$ & 0.417 \\
\hline \multicolumn{5}{|l|}{ Medications at diagnosis N (\%) } \\
\hline ACEI/ARNI & 103 (85.1\%) & 71 (86.5\%) & 32 (82.0\%) & 0.512 \\
\hline$\beta$-blocker & $37(30.5 \%)$ & 30 (36.5\%) & $7(17.9 \%)$ & 0.038 \\
\hline Loop diuretic & $114(94.2 \%)$ & $81(98.7 \%)$ & 33 (84.6\%) & 0.002 \\
\hline Spironolactone & 111 (91.7\%) & 78 (95.1\%) & 33 (84.6\%) & 0.05 \\
\hline Digoxin & $114(94.2 \%)$ & $81(98.7 \%)$ & 33 (84.6\%) & 0.002 \\
\hline \multicolumn{5}{|c|}{$\begin{array}{l}\text { HF, heart failure; LVEDD, left ventricular end-diastolic dimension; LVESD, left ventricular end-systolic } \\
\text { dimension; LVEDPWT, left ventricular end-diastolic posterior wall thickness; LVEDST, left ventricular } \\
\text { end-diastolic septal thickness; ACEI, angiotensin-converting enzyme inhibitors; ARNI, angiotensin II } \\
\text { receptor blocker neprilysin inhibitor. }\end{array}$} \\
\hline
\end{tabular}




\begin{tabular}{|c|c|c|c|c|}
\hline Parameter & $\begin{array}{l}\text { Overall }(n= \\
121)\end{array}$ & $\begin{array}{l}\text { Severe HF (n } \\
=82 \text { ) }\end{array}$ & $\begin{array}{l}\text { Mild HF }(n= \\
39)\end{array}$ & $p$ \\
\hline Intravenous inotropes & $61(50.4 \%)$ & $46(56.1 \%)$ & $15(38.4 \%)$ & 0.07 \\
\hline \multicolumn{5}{|c|}{ LV echocardiographic z scores, (mean \pm SD) } \\
\hline LVEDD z scores & $7.3 \pm 2.8$ & $7.7 \pm 2.6$ & $6.5 \pm 2.8$ & 0.033 \\
\hline LVESD z scores & $10.4 \pm 3.3$ & $10.8 \pm 3.1$ & $9.4 \pm 3.5$ & 0.035 \\
\hline LVEDPWT z scores & $0.9 \pm 2.4$ & $0.9 \pm 2.7$ & $0.9 \pm 1.8$ & 0.99 \\
\hline LVEDST z scores & $0.2 \pm 1.6$ & $0.2 \pm 1.7$ & $0.2 \pm 1.4$ & 0.679 \\
\hline LV fractional shortening z scores & $-8.9 \pm 4.8$ & $-9.1 \pm 5.3$ & $-8.4 \pm 3.7$ & 0.411 \\
\hline LV ejection fraction z scores & $-6.5 \pm 2.1$ & $-7.0 \pm 2.0$ & $-5.6 \pm 2.0$ & 0.001 \\
\hline Mitral regurgitation, $\mathrm{n}(\%)$ & $80(96.6 \%)$ & $80(97.5 \%)$ & $37(94.8 \%)$ & 0.439 \\
\hline Aortic regurgitation, $\mathrm{n}(\%)$ & $10(12.1 \%)$ & $10(12.1 \%)$ & $0(0.0 \%)$ & 0.023 \\
\hline Tricuspid regurgitation, $\mathrm{n}(\%)$ & $10485.9 \%)$ & $74(90.2 \%)$ & $30(76.9 \%)$ & 0.049 \\
\hline Pulmonary regurgitation, n (\%) & $43(35.5 \%)$ & $32(39.0 \%)$ & $11(28.2 \%)$ & 0.245 \\
\hline Follow-up times & $30.5 \pm 42.9$ & $24.4 \pm 40.4$ & $43.2 \pm 45.7$ & 0.024 \\
\hline Events & $83(68.5 \%)$ & $65(79.2 \%)$ & $18(46.1 \%)$ & $\hat{0} .001$ \\
\hline \multicolumn{5}{|c|}{$\begin{array}{l}\text { HF, heart failure; LVEDD, left ventricular end-diastolic dimension; LVESD, left ventricular end-systolic } \\
\text { dimension; LVEDPWT, left ventricular end-diastolic posterior wall thickness; LVEDST, left ventricular } \\
\text { end-diastolic septal thickness; ACEl, angiotensin-converting enzyme inhibitors; ARNI, angiotensin II } \\
\text { receptor blocker neprilysin inhibitor. }\end{array}$} \\
\hline
\end{tabular}

\section{Outcomes}

The median follow-up time was 24.4 months for patients with severe HF and 43.2 months for patients with mild HF ( $P<0.024)$. Of the 82 children with severe HF, 50 (60.9\% at 12 months), 56 (68.3\% at 24 months), 65 (79.2\% at 60 months) and 65 (79.2\%, overall) died, whereas among the 39 children with mild HF, 9 (23.1\% at 12 months), 12 (30.8\% at 24 months), 18 (46.1\% at 60 months) and 18 (46.1\% overall) died $(P<0.001)$. Compared with those with mild $H F$, the time to death was shorter for children with severe HF (Fig. 1, P < 0.001). Cox regression analysis was employed to confirm the factors related to the overall probability of death (Table 2). Severe HF increased the risk of death in unmodulated and in all modulated Cox regression analyses. This relationship was not weakened after modulating for various factors. However, after modulating for use of loop diuretics, severe HF was independently related to a higher risk of death (hazard ratio [HR] 2.27; $95 \% \mathrm{Cl}, 1.28-4.03$ in model 6). In model 6, use of loop diuretics was related to a decreased risk of death (Table 2 , hazard ratio $[\mathrm{HR}] 0.074 ; 95 \% \mathrm{Cl}, 0.006-0.876, \mathrm{p}<0.039$ ). 
Table 2

Multivariate Cox regression modeling of severe heart failure versus mild heart failure.

\begin{tabular}{|c|c|c|c|c|c|c|c|}
\hline Outcome & Variates & $\begin{array}{l}\text { Model } 1 \\
(n=121)\end{array}$ & $\begin{array}{l}\text { Model } 2 \\
(n=121)\end{array}$ & $\begin{array}{l}\text { Model } 3 \\
(n=121)\end{array}$ & $\begin{array}{l}\text { Model } 4 \\
(n=121)\end{array}$ & $\begin{array}{l}\text { Model } 5 \\
(n=121)\end{array}$ & $\begin{array}{l}\text { Model } 6 \\
(n=121)\end{array}$ \\
\hline \multirow[t]{9}{*}{ Death } & $\begin{array}{l}\text { Heart } \\
\text { Failure } \\
\text { (severe vs } \\
\text { mild) }\end{array}$ & $\begin{array}{l}2.516 \\
(1.488- \\
4.255) \\
<0.001\end{array}$ & $\begin{array}{l}2.614 \\
(1.538- \\
4.440) \\
<0.001\end{array}$ & $\begin{array}{l}2.741 \\
(1.603- \\
4.686) \\
<0.001\end{array}$ & $\begin{array}{l}2.625 \\
(1.524- \\
4.620) \\
<0.001\end{array}$ & $\begin{array}{l}2.512 \\
(1.448- \\
4.357) \\
<0.001\end{array}$ & $\begin{array}{l}2.274 \\
(1.280- \\
4.038) \\
<0.005\end{array}$ \\
\hline & $\begin{array}{l}\text { Age } \\
\text { (months) }\end{array}$ & & $\begin{array}{l}0.998 \\
(0.995- \\
1.002) \\
0.329\end{array}$ & $\begin{array}{l}0.998 \\
(0.995- \\
1.002) \\
0.460\end{array}$ & $\begin{array}{l}0.999 \\
(0.996- \\
1.003) \\
0.743\end{array}$ & $\begin{array}{l}0.999 \\
(0.995- \\
1.003) \\
0.558\end{array}$ & $\begin{array}{l}1.000 \\
(0.995- \\
1.004) \\
0.947\end{array}$ \\
\hline & Sex & & & $\begin{array}{l}1.330 \\
(0.854- \\
2.073) \\
0.207\end{array}$ & $\begin{array}{l}1.318 \\
(0.847- \\
2.051) \\
0.221\end{array}$ & $\begin{array}{l}1.283 \\
(0.821- \\
2.006) \\
0.273\end{array}$ & $\begin{array}{l}0.766 \\
(0.475- \\
1.237) \\
0.276\end{array}$ \\
\hline & Heart Rate & & & & $\begin{array}{l}1.005 \\
(0.995- \\
1.016) \\
0.335\end{array}$ & $\begin{array}{l}1.004 \\
(0.993- \\
1.015) \\
0.445\end{array}$ & $\begin{array}{l}1.005 \\
(0.993- \\
1.016) \\
0.418\end{array}$ \\
\hline & $\begin{array}{l}\text { LVEF z } \\
\text { scores }\end{array}$ & & & & & $\begin{array}{l}0.949 \\
(0.857- \\
1.052) \\
0.320\end{array}$ & $\begin{array}{l}0.935 \\
(0.838- \\
1.043) \\
0.225\end{array}$ \\
\hline & $\begin{array}{l}\text { ACEI/ARNI } \\
\text { (yes vs no ) }\end{array}$ & & & & & & $\begin{array}{l}1.214 \\
(0.569- \\
2.588) \\
0.615\end{array}$ \\
\hline & $\begin{array}{l}\beta \text {-blockers } \\
\text { (yes vs no ) }\end{array}$ & & & & & & $\begin{array}{l}1.035 \\
(0.551- \\
1.942) \\
0.915\end{array}$ \\
\hline & $\begin{array}{l}\text { Loop } \\
\text { diuretics } \\
\text { (yes vs no ) }\end{array}$ & & & & & & $\begin{array}{l}0.074 \\
(0.006- \\
0.876) \\
0.039\end{array}$ \\
\hline & $\begin{array}{l}\text { Spirolactone } \\
\text { (yes vs no ) }\end{array}$ & & & & & & $\begin{array}{l}2.338 \\
(0.756- \\
7.232) \\
0.140\end{array}$ \\
\hline
\end{tabular}

Hazard ratios (95\% Cls) and $\mathrm{P}$ values were used to show data. Variates were employed according to the statistics in Table $1(P<0.05)$ or prognostic indicator. Model 1 is a one-variable Cox regression analysis with heart failure (HF) variable (severe HF vs mild HF). Model 2 modulates for age. Model 3 ulteriorly modulates for sex (male/female) besides the variates in Model 2. Model 4 ulteriorly modulates for heart rate besides the variates in Model 3. Model 5 ulteriorly modulates for $\mathrm{LV}$ ejection fraction z score besides the covariates employed in Model 4. Model 6 ulteriorly modulates for drug (including either ACEI or ARNI, and beta blockers, loop diuretics, spironolactone, digoxin and intravenous inotropes) besides the variates employed in Model 5. 


\begin{tabular}{|c|c|c|c|c|c|c|c|}
\hline Outcome & Variates & $\begin{array}{l}\text { Model } 1 \\
(n=121)\end{array}$ & $\begin{array}{l}\text { Model } 2 \\
(n=121)\end{array}$ & $\begin{array}{l}\text { Model } 3 \\
(n=121)\end{array}$ & $\begin{array}{l}\text { Model } 4 \\
(n=121)\end{array}$ & $\begin{array}{l}\text { Model } 5 \\
(n=121)\end{array}$ & $\begin{array}{l}\text { Model } 6 \\
(n=121)\end{array}$ \\
\hline & $\begin{array}{l}\text { Digoxin (yes } \\
\text { vs no) }\end{array}$ & & & & & & $\begin{array}{l}2.421 \\
(0.406- \\
16.912) \\
0.311\end{array}$ \\
\hline & $\begin{array}{l}\text { Intravenous } \\
\text { inotropes } \\
\text { (yes vs no) }\end{array}$ & & & & & & $\begin{array}{l}0.943 \\
(0.577- \\
1.542) \\
0.815\end{array}$ \\
\hline \multicolumn{8}{|c|}{$\begin{array}{l}\text { Hazard ratios ( } 95 \% \mathrm{Cls} \text { ) and } \mathrm{P} \text { values were used to show data. Variates were employed according to } \\
\text { the statistics in Table } 1(\mathrm{P}<0.05) \text { or prognostic indicator. Model } 1 \text { is a one-variable Cox regression } \\
\text { analysis with heart failure }(\mathrm{HF}) \text { variable (severe } \mathrm{HF} \text { vs mild HF). Model } 2 \text { modulates for age. Model } 3 \\
\text { ulteriorly modulates for sex (male/female) besides the variates in Model } 2 \text {. Model } 4 \text { ulteriorly } \\
\text { modulates for heart rate besides the variates in Model } 3 \text {. Model } 5 \text { ulteriorly modulates for LV ejection } \\
\text { fraction z score besides the covariates employed in Model } 4 \text {. Model } 6 \text { ulteriorly modulates for drug } \\
\text { (including either ACEl or ARNI, and beta blockers, loop diuretics, spironolactone, digoxin and } \\
\text { intravenous inotropes) besides the variates employed in Model } 5 \text {. }\end{array}$} \\
\hline
\end{tabular}

\section{Discussion}

The study demonstrates that children with DCM and severe HF at diagnosis were older, more likely to be male, have lower systolic blood pressure measurements, be admitted to the ICU and be treated with $\beta$ blockers, loop diuretics, spironolactone and digoxin. They are also more likely to have larger diastolic LV end-diastolic dimensional z-scores and poorer LV function. Compared with children with DCM and mild $\mathrm{HF}$, those with DCM and severe HF at diagnosis were at a higher risk of death. Severe HF was related to an accumulated risk of death. These associations were not affected by sex, age at diagnosis, heart rate, ventricular function and use of medication.

These results are similar to those found in a study by Rusconi [11]. They showed similar results with respect to survival between family-associated DCM and idiopathic DCM after modulation for other variates. However, HF, older age, and larger left ventricular end-diastolic dimension (LVEDD) at diagnosis were independently related to increased risks of the major adverse events of heart transplantation or death. In a retrospective analysis, HF with NYHA III/IV were significantly associated with overall death risk[12]. A meta-analysis of 57 researches of medication adherence interventions for HF treatment from adults found an obvious association between improvement of HF and a decrease of mortality[13]. These findings lend support to the idea that an improvement in HF may be a key goal for DCM therapy.

Angiotensin-converting enzyme inhibitors (ACEI) is the cornerstone of HF treatment and can significantly improve cardiac remodeling. The beneficial effects of ACEI for HF in children with DCM have been proven in previous studies[14, 15]. One prospective and large-sample study which included 5,955 adult patients with DCM and LVEF $<40 \%$ also confirmed that use of ACEI was related to the recovery of the LVEF coupled with an improvement of HF at 3 years of follow-up[16]. In a European survey between pediatric HF and ACEl use patterns conducted between January and May 2015, ACEl appeared to be essential in 
pediatric HF treatment strategies[17]. Nowadays, the angiotensin II receptor blocker, neprilysin inhibitor (ARNI), is more effective when compared with ACEl, and this drug has now been recommended to be the preferred treatment in patients with $\operatorname{HF}[8,9,18]$.

In children with DCM and HF, elevated heart rate is often accompanied by worsening HF. Thus, the heart rate may be a target for HF treatment. Beta blockers can reduce heart rate. Three meta-analysis on the use of beta-blockers for congestive HF in children showed that children with congestive HF might benefit from treatment with these drugs[19-21]. Additionally, ivabradine is a novel drug which can reduce the heart rate. A study randomized 116 patients diagnosed with DCM and class II to IV HF. In this study, the heart rate was reduced by $\geq 20 \%$ from baseline without leading to symptoms or bradycardia were more likely to occur in the patients taking ivabradine rather than taking the placebo. This reduction was accompanied with a significant increase in the LVEF, an improvement of the cardiac function as well as in the quality of life[22]. Another adult study also showed that the reduction of heart rate in the ivabradine group could improve the prognosis of HF[23].

In our study, loop diuretics was related to a decreased risk of death. Diuretics are also another important treatment for HF. A meta-analysis of 14 studies with 525 participants of the use of diuretic in HF suggested that these were able to reduce mortality and retard progression of HF [24]. In a study of 25,345 elder patients with HF, patients with loop diuretics as a discharge prescription had a better clinical improvement comparing with those not taking loop diuretics[25]. One study included 108 children and showed that an increase of loop diuretic responsiveness during the first 72 hours of treatment was accompanied by shorter length of hospital stays and a decrease of inpatient deaths or use of mechanical circulatory support[26]. In addition to loop diuretics, a mineralocorticoid receptor antagonist (MRA), such as spironolactone, which can also have a diuretic effect, is fundamental during the long-term management of HF[27].

There are several emerging treatments for HF in children with DCM. In a meta-analysis study, sodiumglucose co-transporter-2 (SGLT2) inhibitors were shown to reduce all-cause and cardiovascular death in patients with HF [28], and these drugs are recommended to be the preferred choice of treatment in patients with $\mathrm{HF}[8,9]$. Pulmonary artery banding (PAB) treatment, as a new indication for end-stage DCM in pediatric patients, has also been shown to be safe and effective[29, 30]. Left ventricular mechanical assist can be indicated as destination therapy for end-stage DCM[31]. Cardiac pacemaker can be an effective tool for treating HF, especially in patients who have a complete left bundle branch block[32]. Cardiac stem cell therapy is yet another feasible and safe treatment in children with DCM and HF, and can improve left ventricular function[33]. If none of the above methods work, heart transplantation could be considered as a last resort[34].

As we have already confirmed that severe HF is related to a higher risk of death in children with DCM, so therapies that improve HF can increase survival. Through a more comprehensive understanding of DCM, especially with respect to the genetics of DCM and the potential of finding new early markers and treatment for HF, it is envisaged that the treatment of HF caused by DCM will become more personalized 
and lead to earlier interventions [35-37]. Thus, a larger and prospective study combining all these factors should be performed to evaluate the efficacy between the treatment of HF and outcomes in children with DCM.

\section{Limitations}

Several limitations were included in this study. Assessment of cardiac functions is often difficult and a lack of objectivity can occur due to non-cooperation of young children. Echocardiography was usually not performed by the same doctor. This may have introduced error measurements into the research. This just was a small-sample and retrospective research in one single center and therefore prone to biases and limitations. Further larger-sample and prospective researches are warranted to verify our conclusions. Finally, selection bias was existed due to the nature of the retrospective study.

\section{Conlusions}

It was concluded that severe HF at diagnosis was related to a higher risk of death. The result shows that improvement of HF may be a primary goal of therapy and can potentially increase the survival in children with DCM. Further prospective studies are warranted to evaluate the efficacy between the treatment of HF and outcomes in children with DCM.

\section{Abbreviations}

DCM

Dilated cardiomyopathy

$\mathrm{HF}$

Heart failure

LVEDD

left ventricular end-diastolic dimension

SDs

standard deviations

LVESD

left ventricular end-systolic dimension

LVEDPWT

left ventricular end-diastolic posterior wall thickness

LVEDST

left ventricular end-diastolic septal thickness LVEF:left ventricular ejection fraction

LVFS

left ventricular fractional shortening

BMI

body mass index

$\mathrm{HR}$ 
Hazard ratios

$\mathrm{Cl}$

confidence intervals

ACEI

Angiotensin-converting enzyme inhibitors

ARNI

neprilysin inhibitor

MRA

mineralocorticoid receptor antagonist

SGLT2

sodium-glucose co-transporter-2

PAB

pulmonary artery banding.

\section{Declarations}

\section{ACKNOWLEDGEMENTS}

Thanks for the help of all the working partners of the first Ward of Pediatrics in our hospital and http://zscore.chboston.org for z-score calculation during the preparation of this manuscript. The authors thank Dr Dev Sooranna of Imperial College London for editing the manuscript.

\section{AUTHOR CONTRIBUTIONS}

CC contributed to study design and drafted the article. DS, SQ, YH and WZ contributed to statistical analysis, BY, YH and DL collected data. YP contributed to the concept of the research and the edited manuscript. All authors took part in drafting article and had their permission for publication.

\section{FUNDING}

This study was funded by a grant from the Scientific Research Project of Guangxi Health Planning Commission (Grant no. Z20210993).

\section{Availability of data and materials}

All data generated or analyzed during this study are included in this published article and its supplementary information files.

\section{Ethics approval and consent to participate}

This study was approved by the Ethics Committee of the First Affiliated Hospital of Guangxi Medical University (NO. 2022(KY-E-007)) and carried out in accordance with the principles of the Declaration of Helsinki (as revised in 2013). Informed consent was obtained from their legal guardians. 
Consent for publication

Not applicable.

Competing interests

The authors declare that they have no competing interests.

\section{References}

1. SE L, YM L, A A-K, ED A, AI D, MD E, DT H, KY L, JF P, JD W et al: Cardiomyopathy in Children: Classification and Diagnosis: A Scientific Statement From the American Heart Association. Circulation 2019, 140(1):e9-e68.

2. JA T, AM L, SD C, LA S, EJ O, S C, J M, GF C, PR L, D H et al: Incidence, causes, and outcomes of dilated cardiomyopathy in children. JAMA 2006, 296(15):1867-1876.

3. Nugent AW, Daubeney PE, Chondros P, Carlin JB, Cheung M, Wilkinson LC, Davis AM, Kahler SG, Chow CW, Wilkinson JL et al: The epidemiology of childhood cardiomyopathy in Australia. N Engl J Med 2003, 348(17):1639-1646.

4. Singh RK, Canter CE, Shi L, Colan SD, Dodd DA, Everitt MD, Hsu DT, Jefferies JL, Kantor PF, Pahl E et al: Survival Without Cardiac Transplantation Among Children With Dilated Cardiomyopathy. J Am Coll Cardiol 2017, 70(21):2663-2673.

5. Rossano JW, Kim JJ, Decker JA, Price JF, Zafar F, Graves DE, Morales DL, Heinle JS, Bozkurt B, Towbin JA et al: Prevalence, morbidity, and mortality of heart failure-related hospitalizations in children in the United States: a population-based study. J Card Fail 2012, 18(6):459-470.

6. Kasten J, Rakheja D, Zhang S, Thankavel P, Das BB: Reverse histologic remodeling after mechanical unloading of failing hearts in children with dilated cardiomyopathy. The Journal of heart and lung transplantation: the official publication of the International Society for Heart Transplantation 2017, 36(11):1268-1271.

7. Rupp S, Apitz C, Tholen L, Latus H, Ostermayer SH, Schmidt D, Bauer J, Schranz D: Upgraded heart failure therapy leads to an improved outcome of dilated cardiomyopathy in infants and toddlers. Cardiology in the young 2015, 25(7):1300-1305.

8. McDonagh TA, Metra M, Adamo M, Gardner RS, Baumbach A, Böhm M, Burri H, Butler J, Čelutkienė J, Chioncel $O$ et al: 2021 ESC Guidelines for the diagnosis and treatment of acute and chronic heart failure. Eur Heart J 2021, 42(36):3599-3726.

9. Maddox T, Januzzi J, Allen L, Breathett K, Butler J, Davis L, Fonarow G, Ibrahim N, Lindenfeld J, Masoudi F et al: 2021 Update to the 2017 ACC Expert Consensus Decision Pathway for Optimization of Heart Failure Treatment: Answers to 10 Pivotal Issues About Heart Failure With Reduced Ejection Fraction: A Report of the American College of Cardiology Solution Set Oversight Committee. Journal of the American College of Cardiology 2021, 77(6):772-810. 
10. Ross RD, Bollinger RO, Pinsky WW: Grading the severity of congestive heart failure in infants. Pediatr Cardiol 1992, 13(2):72-75.

11. Rusconi P, Wilkinson J, Sleeper L, Lu M, Cox G, Towbin J, Colan S, Webber S, Canter C, Ware S et al: Differences in Presentation and Outcomes Between Children With Familial Dilated Cardiomyopathy and Children With Idiopathic Dilated Cardiomyopathy: A Report From the Pediatric Cardiomyopathy Registry Study Group. Circulation Heart failure 2017, 10(2).

12. Dziewięcka E, Gliniak M, Winiarczyk M, Karapetyan A, Wiśniowska-Śmiałek S, Karabinowska A, Dziewięcki $\mathrm{M}$, Podolec $\mathrm{P}$, Rubiś $\mathrm{P}$ : Mortality risk in dilated cardiomyopathy: the accuracy of heart failure prognostic models and dilated cardiomyopathy-tailored prognostic model. ESC heart failure 2020.

13. Ruppar TM, Cooper PS, Mehr DR, Delgado JM, Dunbar-Jacob JM: Medication Adherence Interventions Improve Heart Failure Mortality and Readmission Rates: Systematic Review and MetaAnalysis of Controlled Trials. J Am Heart Assoc 2016, 5(6).

14. Stern H, Weil J, Genz T, Vogt W, Bühlmeyer K: Captopril in children with dilated cardiomyopathy: acute and long-term effects in a prospective study of hemodynamic and hormonal effects. Pediatr Cardiol 1990, 11(1):22-28.

15. Lewis $A B$, Chabot $M$ : The effect of treatment with angiotensin-converting enzyme inhibitors on survival of pediatric patients with dilated cardiomyopathy. Pediatr Cardiol 1993, 14(1):9-12.

16. Enzan N, Matsushima S, Ide T, Kaku H, Tohyama T, Funakoshi K, Higo T, Tsutsui H: The Use of Angiotensin-Converting Enzyme Inhibitors or Angiotensin II Receptor Blockers Is Associated with the Recovered Ejection Fraction in Patients with Dilated Cardiomyopathy. International heart journal 2021, 62(4):801-810.

17. Castro Díez C, Khalil F, Schwender H, Dalinghaus M, Jovanovic I, Makowski N, Male C, Bajcetic M, van der Meulen M, de Wildt SN et al: Pharmacotherapeutic management of paediatric heart failure and ACE-I use patterns: a European survey. BMJ paediatrics open 2019, 3(1):e000365.

18. Paolini C, Mugnai G, Dalla Valle C, Volpiana A, Ferraglia A, Frigo AC, Bilato C: Effects and clinical implications of sacubitril/valsartan on left ventricular reverse remodeling in patients affected by chronic heart failure: A 24-month follow-up. International journal of cardiology Heart \& vasculature 2021, 35:100821.

19. Frobel AK, Hulpke-Wette M, Schmidt KG, Läer S: Beta-blockers for congestive heart failure in children. The Cochrane database of systematic reviews 2009(1):Cd007037.

20. Alabed S, Sabouni A, Al Dakhoul S, Bdaiwi Y, Frobel-Mercier AK: Beta-blockers for congestive heart failure in children. The Cochrane database of systematic reviews 2016(1):Cd007037.

21. Alabed S, Sabouni A, Al Dakhoul S, Bdaiwi Y: Beta-blockers for congestive heart failure in children. The Cochrane database of systematic reviews 2020, 7(7):Cd007037.

22. Bonnet D, Berger F, Jokinen E, Kantor PF, Daubeney PEF: Ivabradine in Children With Dilated Cardiomyopathy and Symptomatic Chronic Heart Failure. J Am Coll Cardiol 2017, 70(10):12621272. 
23. Swedberg K, Komajda M, Böhm M, Borer JS, Ford I, Dubost-Brama A, Lerebours G, Tavazzi L: Ivabradine and outcomes in chronic heart failure (SHIFT): a randomised placebo-controlled study. Lancet 2010, 376(9744):875-885.

24. Faris RF, Flather M, Purcell H, Poole-Wilson PA, Coats AJ: Diuretics for heart failure. The Cochrane database of systematic reviews 2012(2):Cd003838.

25. Faselis C, Arundel C, Patel S, Lam PH, Gottlieb SS, Zile MR, Deedwania P, Filippatos G, Sheriff HM, Zeng Q et al: Loop Diuretic Prescription and 30-Day Outcomes in Older Patients With Heart Failure. J Am Coll Cardiol 2020, 76(6):669-679.

26. Price JF, Younan S, Cabrera AG, Denfield SW, Tunuguntla H, Choudhry S, Dreyer WJ, Akcan-Arikan A: Diuretic Responsiveness and Its Prognostic Significance in Children With Heart Failure. J Card Fail 2019, 25(12):941-947.

27. Chen $Y$, Wang H, Lu Y, Huang X, Liao Y, Bin J: Effects of mineralocorticoid receptor antagonists in patients with preserved ejection fraction: a meta-analysis of randomized clinical trials. BMC medicine 2015, 13:10.

28. Zannad F, Ferreira JP, Pocock SJ, Anker SD, Butler J, Filippatos G, Brueckmann M, Ofstad AP, Pfarr E, Jamal W et al: SGLT2 inhibitors in patients with heart failure with reduced ejection fraction: a metaanalysis of the EMPEROR-Reduced and DAPA-HF trials. Lancet 2020, 396(10254):819-829.

29. Schranz D, Akintuerk H, Bailey L: Pulmonary Artery Banding for Functional Regeneration of EndStage Dilated Cardiomyopathy in Young Children: World Network Report. Circulation 2018, 137(13):1410-1412.

30. Schranz D, Rupp S, Müller M, Schmidt D, Bauer A, Valeske K, Michel-Behnke I, Jux C, Apitz C, Thul J et al: Pulmonary artery banding in infants and young children with left ventricular dilated cardiomyopathy: a novel therapeutic strategy before heart transplantation. The Journal of heart and lung transplantation: the official publication of the International Society for Heart Transplantation 2013, 32(5):475-481.

31. Perri G, Filippelli S, Adorisio R, lacobelli R, lodice F, Testa G, Paglietti MG, D'Amario D, Massetti M, Amodeo A: Left ventricular assist device as destination therapy in cardiac end-stage dystrophinopathies: Midterm results. The Journal of thoracic and cardiovascular surgery 2017, 153(3):669-674.

32. Motonaga KS, Dubin AM: Cardiac resynchronization therapy for pediatric patients with heart failure and congenital heart disease: a reappraisal of results. Circulation 2014, 129(18):1879-1891.

33. Pincott ES, Ridout D, Brocklesby M, McEwan A, Muthurangu V, Burch M: A randomized study of autologous bone marrow-derived stem cells in pediatric cardiomyopathy. The Journal of heart and lung transplantation: the official publication of the International Society for Heart Transplantation 2017, 36(8):837-844.

34. Tsirka AE, Trinkaus K, Chen SC, Lipshultz SE, Towbin JA, Colan SD, Exil V, Strauss AW, Canter CE: Improved outcomes of pediatric dilated cardiomyopathy with utilization of heart transplantation. $J$ Am Coll Cardiol 2004, 44(2):391-397. 
35. Verdonschot JAJ, Merlo M, Dominguez F, Wang P, Henkens M, Adriaens ME, Hazebroek MR, Masè M, Escobar LE, Cobas-Paz R et al: Phenotypic clustering of dilated cardiomyopathy patients highlights important pathophysiological differences. Eur Heart J 2021, 42(2):162-174.

36. Kayvanpour E, Sedaghat-Hamedani F, Amr A, Lai A, Haas J, Holzer DB, Frese KS, Keller A, Jensen K, Katus HA et al: Genotype-phenotype associations in dilated cardiomyopathy: meta-analysis on more than $\mathbf{8 0 0 0}$ individuals. Clinical research in cardiology: official journal of the German Cardiac Society 2017, 106(2):127-139.

37. Hauser JA, Demyanets S, Rusai K, Goritschan C, Weber M, Panesar D, Rindler L, Taylor AM, Marculescu R, Burch $M$ et al: Diagnostic performance and reference values of novel biomarkers of paediatric heart failure. Heart 2016, 102(20):1633-1639.

\section{Figures}

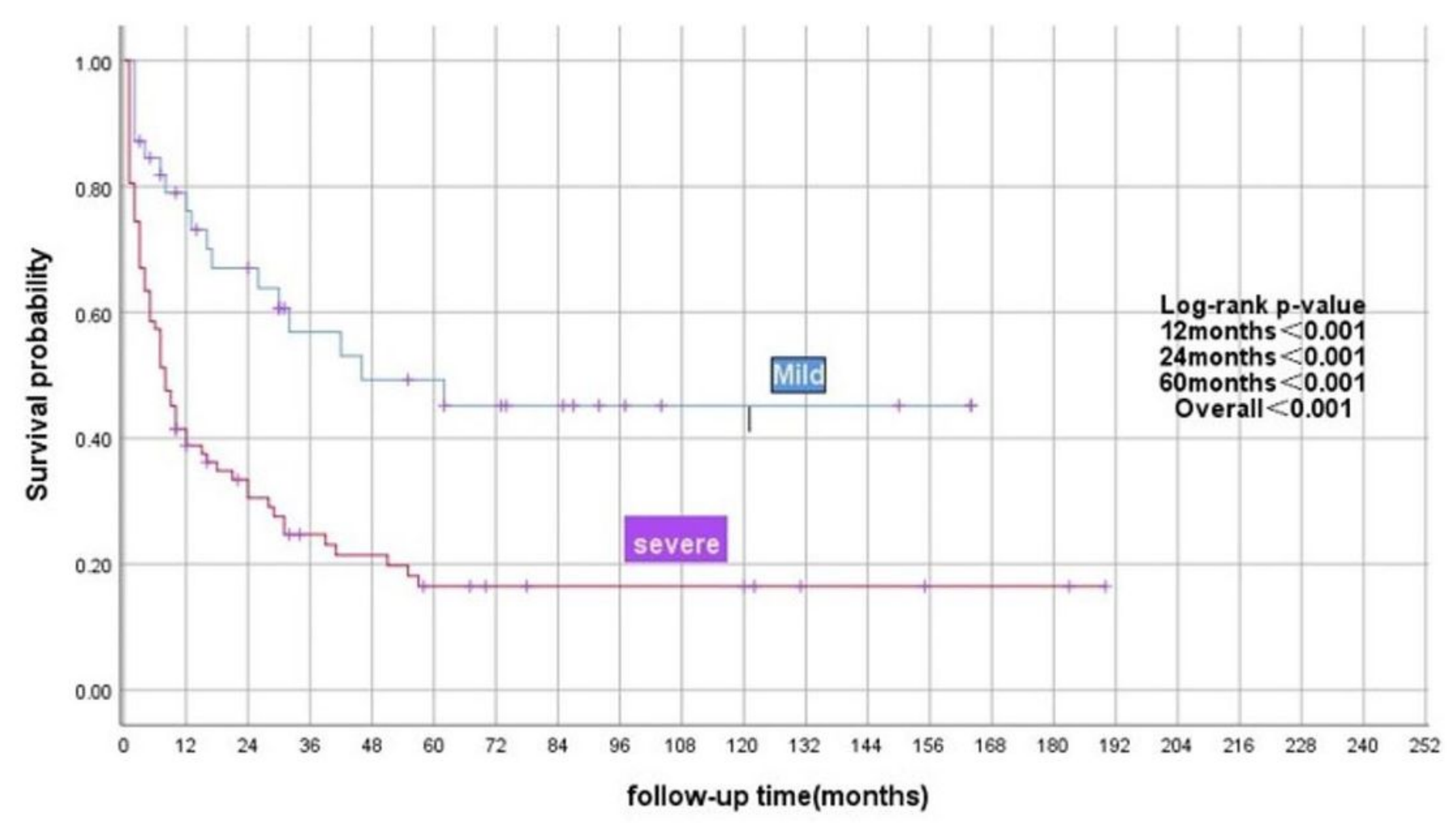

Number of accumulative death

$\begin{array}{lrrrrr}\text { Severe } & 50 & 56 & 60 & 65 & 65 \\ \text { Mild } & 9 & 12 & 15 & 17 & 18\end{array}$

\section{Figure 1}

Survival analysis in severe and mild heart failure. The time to death was shorter for children with severe $H F$, compared with those having mild HF. Log-rank testing $P$ values for survival at 12, 24, and 60 months 
after diagnosis of dilated cardiomyopathy were $<0.001$.

\section{Supplementary Files}

This is a list of supplementary files associated with this preprint. Click to download.

- dataSevereHeartFailureandOutcomesin121ChildrenWithDilatedCardiomyopathy.xls 